\title{
A Man With Whipple's Triad Secondary to a Malignant Insulinoma
}

\author{
Waiel A. Basharia ${ }^{a}$ Naomi E. Riddel ${ }^{\mathrm{a}}$, Samson O. Oyibo ${ }^{\mathrm{a}, \mathrm{b}}$
}

\begin{abstract}
Insulinomas are neuroendocrine tumors of the pancreas that are derived from the beta cells and secrete insulin. They are rare and most are benign growths within the pancreas. We present a patient who had a long history of symptoms suggestive of recurrent fasting hypoglycemia and was subsequently found to have a small malignant insulinoma within his pancreas requiring extensive surgery.
\end{abstract}

Keywords: Whipple's triad; Hyperinsulinemia; Insulinoma

\section{Introduction}

Insulinomas are the commonest type of pancreatic neuroendocrine tumors. However, they are rare with an incidence of 3 - 10 new cases per million people per year [1]. A majority of tumors are benign, single and sporadic but about $10 \%$ can occur as part of the multiple endocrine neoplasia type 1 (MEN1) syndrome and about $5-30 \%$ of new cases can be malignant. Affected patients have inappropriately high plasma insulin levels in the presence of low plasma glucose levels.

Patients typically present with three features: symptoms of fasting hypoglycemia, a plasma glucose below $2.5 \mathrm{mmol} / \mathrm{L}$ measured at the time of symptoms and symptoms are relieved by administration of glucose, raising plasma glucose to normal levels. This group of features which constitute the Whipple's triad was described by Whipple in the 1930s [2].

We present a patient who had a long history of symptoms suggestive of recurrent fasting hypoglycemia and was subsequently found to have a small malignant insulinoma requiring extensive surgery.

Manuscript accepted for publication May 19, 2015

aDepartment of Diabetes \& Endocrinology, Peterborough City Hospital, Peterborough, UK

${ }^{b}$ Corresponding Author: Samson Oyibo, Department of Diabetes \& Endocrinology, Peterborough City Hospital, Bretton Gate, Peterborough PE3 9GZ, UK.Email: samoyibo@yahoo.co.uk

doi: http://dx.doi.org/10.14740/jmc2175w

\section{Case Report}

A 69-year-old gentleman was presented to the endocrine team in July 2014 with a 2-week history of recurrent symptoms of hypoglycemia with plasma glucose levels below $2.5 \mathrm{mmol} / \mathrm{L}$. At the time he was an inpatient on the orthopedic ward with an infected prosthetic knee joint being treated with antibiotics. He was also on ramipril and amlodipine for hypertension.

Since September 2013, he had been having recurrent episodes of aggression towards his family members and excessive sweating. His general practitioner found him to have a low capillary blood glucose level at one time and gave him a blood glucose monitoring device for self-checks. He used the monitoring device frequently and discovered that his capillary blood glucose levels were below $3 \mathrm{mmol} / \mathrm{L}$ on several occasions throughout the day. Since then he always kept eating a large amount of sugar-containing meals and snacks to keep his blood glucose levels up and felt fine.

On examination he was an overweight gentleman $(115 \mathrm{~kg}$, body mass index of $36.4 \mathrm{~kg} / \mathrm{m}^{2}$ ). A review of his capillary glucose monitoring charts confirmed daily and multiple episodes of hypoglycemia based on capillary blood glucose and laboratory plasma glucose readings below $2.5 \mathrm{mmol} / \mathrm{L}$. We confirmed that he was not taking any insulin products or any oral anti-diabetic medication (e.g. sulphonylureas).

We performed a 72-h fast to enable us to measure his plasma glucose, proinsulin, insulin and C-peptide levels during a hypoglycemic event. Samples were obtained on two occasions, both confirming severe hyperinsulinemia in the presence of severe hypoglycemia (Table 1). Tests for full blood count, liver function, thyroid function, renal function, calcium and prolactin estimations were normal. A short synacthen test ruled out adrenal dysfunction, and his gut hormone profile was also normal. A computerized tomography (CT) scan of his abdomen which was reported as normal apart from a bulky left adrenal gland: biochemical investigations confirmed a coincidental non-functioning adrenal adenoma.

He was initially started on diazoxide $50 \mathrm{mg}$ orally three times a day for relief of hypoglycemic symptoms. He was subsequently referred for an endoscopic ultrasound, which revealed a $1.5 \mathrm{~cm}$ hypoechoic lesion in the head of the pancreas. This was treated by surgical excision of the head of his pancreas, his gall bladder, the first and second part of his duodenum and the distal part of his stomach (Whipple's procedure). 
Table 1. Results of Blood Tests During the Patient's Hypoglycemic Episodes

\begin{tabular}{llll} 
Biochemical test & Reference range* $^{*}$ & First sample & Secnd sample \\
\hline Plasma glucose & $<3 \mathrm{mmol} / \mathrm{L}$ & 2.0 & 2.5 \\
Plasma insulin & $>3 \mathrm{pmol} / \mathrm{L}$ & 119 & 103 \\
Plasma proinsulin & $>5 \mathrm{pmol} / \mathrm{L}$ & $>300$ & $>300$ \\
Plasma C-peptide & $>0.2 \mathrm{nmol} / \mathrm{L}$ & 2.53 & 3.05 \\
\hline
\end{tabular}

*Diagnostic criteria for hyperinsulinemia during a hypoglycemic episode [3].

Pathological examination after surgical excision revealed an $18 \mathrm{~mm}$ ovoid grey nodule within the head of the pancreas. This had the histological features of a well-differentiated neuroendocrine carcinoma (World Health Organization (WHO) grade 1). There was also evidence of small calibre vascular invasion and intra-parenchymal metastatic spread to the ampulla and to one lymph node.

Diazoxide was stopped after the surgery and he has not had any more hypoglycemic symptoms. He currently takes a pancreatic supplement and omeprazole for indigestion, along with his previous antihypertensive medication. He now weighs $96 \mathrm{~kg}$, has stopped taking pure sugar altogether, and is having follow-up for any gastrointestinal symptoms and for the coincidental left adrenal adenoma.

\section{Discussion}

Although insulinomas are usually benign, the inappropriately high circulating levels of insulin cause symptomatic and lifethreatening hypoglycemia during fasting periods or during exercise. Symptoms are relieved by ingesting glucose-containing substances.

The diagnosis of an insulinoma depends largely on a high degree of clinical suspicion. All patients present with the features that make up the Whipple's triad. The importance of taking a thorough history cannot be overemphasized, especially for medications that can cause hypoglycemia. After excluding endocrine failures and other causes of hypoglycemia the patient should have blood samples taken for glucose, insulin, proinsulin, and C-peptide during a spontaneous or recreated hypoglycemic event (e.g. 72-h fast). Samples for drug screen and insulin antibodies should also be taken to rule out druginduced causes. The combination of symptoms and signs of hypoglycemia with the biochemical criteria (plasma glucose below $3.0 \mathrm{mmol} / \mathrm{L}$, proinsulin above $5.0 \mathrm{pmol} / \mathrm{L}$, insulin above $3.0 \mathrm{pmol} / \mathrm{L}$, and C-peptide above $0.2 \mathrm{nmol} / \mathrm{L}$ ) all demonstrate endogenous hyperinsulinemia [3]. The discovery of such hyperinsulinemia should prompt the need for localization imaging such as computed tomography, magnetic resonance imaging, endoscopic ultrasonography, and if required, selective pancreatic arterial calcium injections with hepatic venous insulin measurements [3].

Hypoglycemic events can be prevented by treatment with diazoxide while the patient is being considered for surgery. Diazoxide is a potassium channel activator that increases plasma glucose levels possibly through a combination of reducing insulin secretion from the pancreas and increasing glucose output from the liver [4]. The definitive treatment for an insulinoma is surgery, which can range from simple enucleation for small lesions in the pancreas to partial pancreatectomy as part of the Whipple's procedure for more extensive disease. Our patient had a small malignant insulinoma in the head of the pancreas with metastasis to the ampulla and to a single lymph node. This was a well-differentiated (grade 1) lesion according to the WHO classification system $[5,6]$. The Whipple's procedure was required for this stage of disease.

In conclusion, we present a man with a long history of symptoms of hypoglycemia relieved by sugary snacks and drinks, who was subsequently found to have a small malignant insulinoma in his pancreas. The fact that this lesion was very small and malignant makes this case unique. This case also highlights the importance of remembering the age-old Whipple's triad while taking a history for the early detection of this life-threatening condition.

\section{Conflict of Interest}

The authors declare that there is no conflict of interests regarding the publication of this article.

\section{References}

1. Dadan J, Wojskowicz P, Wojskowicz A. Neuroendocrine tumors of the pancreas. Wiad Lek. 2008;61(1-3):43-47.

2. van Heerden JA, Edis AJ, Service FJ. The surgical aspects of insulinomas. Ann Surg. 1979;189(6):677-682.

3. Cryer PE, Axelrod L, Grossman AB, Heller SR, Montori VM, Seaquist ER, Service FJ. Evaluation and management of adult hypoglycemic disorders: an Endocrine Society Clinical Practice Guideline. J Clin Endocrinol Metab. 2009;94(3):709-728.

4. Altszuler N, Moraru E, Hampshire J. On the mechanism of diazoxide-induced hyperglycemia. Diabetes. 1977;26(10):931-935.

5. Chen M, Van Ness M, Guo Y, Gregg J. Molecular pathology of pancreatic neuroendocrine tumors. J Gastrointest Oncol. 2012;3(3):182-188.

6. Klimstra DS, Modlin IR, Coppola D, Lloyd RV, Suster S. The pathologic classification of neuroendocrine tumors: a review of nomenclature, grading, and staging systems. Pancreas. 2010;39(6):707-712. 